\title{
Case Study of Biomass Development Policy Model in West Sumbawa Region
}

\author{
Erwin Susanto Sadirsan ${ }^{\mathrm{a} *}$, Hermanto Siregar ${ }^{\mathrm{b}}$, Eriyatno $^{\mathrm{c}}$, Evita H. Legowo ${ }^{\mathrm{d}}$ \\ ${ }^{a}$ Darma Persada University, Jalan Raden Inten Jakarta, Indonesia \\ ${ }^{b}$ Bogor Institute of Agriculture, Jalan Pajajaran Bogor Indonesia \\ ${ }^{c}$ Bogor Institute of Agriculture Jl. Pajajaran, Bogor, Indonesia \\ ${ }^{d}$ Swiss Germany University, Serpong, Tangerang, Indonesia
}

\begin{abstract}
This study aims to develop renewable energy policy models concerning biomass for rural electrification; to identify factors that influence price of feed in tariff determination, in particular wood-based biomass,; and designing the role of social forest as raw materials for bio-pellet industry in sustainable supply chain. Research method using soft systems methodology is the application of Interpretative Structural Modeling (ISM) and Strategic Assumption Surfacing and Testing (SAST). The results showed that key elements of development policy model are feasible biomass energy tariff, competent human resources, coordination among related local government offices and community participation. It requires support regulatory from local governments, inventory of land use and forest area, and support of community leaders.
\end{abstract}

Keywords: bio-pellet industry; feed in tariff; Interpretative Structural Modeling ; SAST; social forest

\section{Introduction}

Indonesia as one of the oil producing countries has a high export potential, but unfortunately is currently a net importer. Fuel consumption is about 1.4 million barrels of oil per day (BOPD), while production is about 940 thousand BOPD. Imbalance of supply and demand has resulted in enormous imports. Subsidies for fuel and electricity are very large over USD 300 trillion and conditions of fluctuating oil prices reached $\$ 140$ per barrel resulting in a very heavy burden on the government. Development of alternative energy from new and renewable energy is a solution to reduce dependency on imported oil.

Development of alternative energy, in accordance with the Presidential Decree.No.5 year 2006, mandated that energy mix to renewable energy by 17 percent by 2025. Implementation of this policy through Minister of Energy and Mineral Resources Regulation No.4 in 2012 specifically regard to biomass Feed in Tariff, and number 19 year 2013 for waste products FIT. The revision to complement and reinforce the development of new and renewable energy, requires policies that regulates the feed-in tariff for bio-pellet.

Under these circumstances the research aims are: (i) identifying factors that influence development of renewable biomass energy policy, based on forest biomass managed by people (ii) designing bio-pellet industry supply chain system with sustainable empowerment of community forests, and (iii) developing renewable energy policy of biomass based industry, for rural electrification.

\footnotetext{
* Corresponding author. Tel.: + 062811814402

E-mail address: erwin.sadirsan@medcoenergi,com
} 


\section{Literature review and previous research}

The biomass is one of the renewable energy sources that has an important role and will continue to grow and develop in the world. The latest development shown in China, which have a huge biomass development that reaches 3511 MTCE (million tons of coal equivalent). The Biomass in China is highly distributed depends on the geography and climate in various provinces. Yet, the development of biomass in China still needs incentive and feed-in tariff policies, capital goods subsidy, and research and development expenses including tax incentives and pricing. Derivative biomass energy distributed varies from one province to another in China. The highest biomass energy found in Tibet amounting to 14.17 tee (tons of energy equivalent) per capita in Tibet while the smallest one is 0.15 tee in Sechiang [1].

The Feed-in Tariff Policy in the US is still not feasible. This is because the data and the literature shown that Feed-in Tariff Policy for solar energy is not right yet. The implementation of such policy will depend on the type of technology used that need to be elaborated further. The limitation policy up to capacity 20 MW to enjoy incentives, seems to be restricted. In Germany there is no such limitation. This restriction makes Feed-in Tariffs in America seems unsupportive to the development of renewable energy. Most of the highly developed countries are caring about security and availability of renewable energy, as an example Netherland having a minimum target of $10 \%$ renewable energy consumption in 2020 and had reached $5 \%$ in 2006 .

The implications of social forestry is the establishment of coordination institution at the district level in the form of Working Group which is a representation of the various parties associated with the administration of social forestry program. Working Group provides strategic policy guidance into each party working program. Vision of the Working Group is taking a role as the coordination agency for realizing the plantations business continuity run by the community. The Working Group also became the center of mentoring activities undertaken by forestry scholars in India. Based on previous study, Eswarlal identifies 14 key variables influencing the performance of renewable energy. Based on ISM analysis, those hierarchy are shown on the Figure 1. 


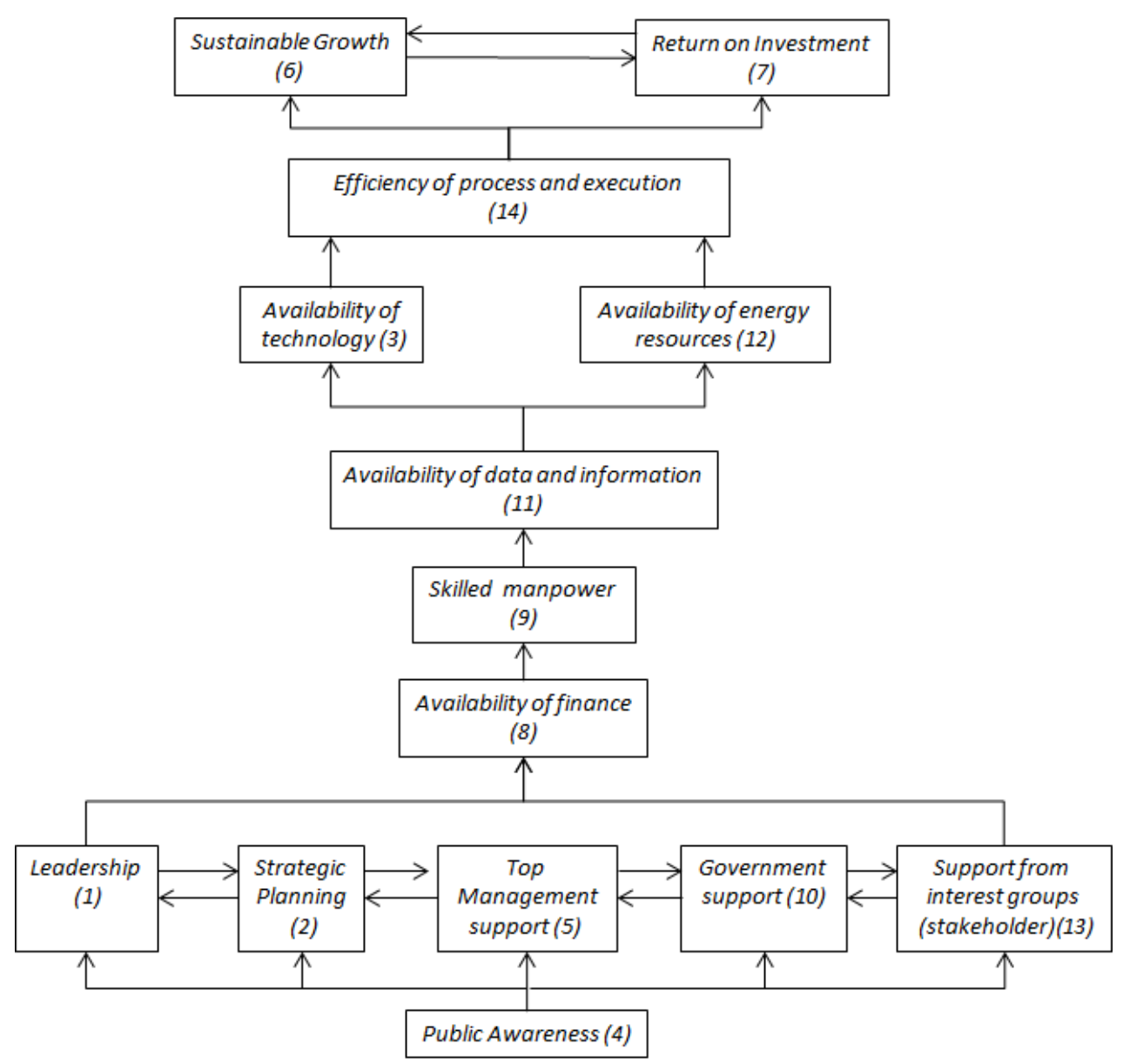

Figure 1. ISM model-based.

Figure 1 shows an overall view issues in new and renewable energy implementation for policy makers. The picture identified variables that affect the performance of the process and the relationship between these variables. Figure 1 also shows that the public awareness about new and renewable energy (the 4th variable) is an important variable since it has the highest driving power and nil dependence power. The variable is very significant and drives all other variables. Therefore, policy maker must focus on the public awareness in renewables energy implementation for development sustainability success. Public awareness about new and renewable energy will trigger top management support (5th variable). On the other hand, management leadership quality (1st variable) will be functioned only if top management provide support. Good strategic planning (2nd variable) need managerial leadership quality and top management support. Support from stakeholder group (13th variable) will not be realized if top management support does not exist.

The studies above are on regional basis, highlight government role in each country on encouraged biomass use and reduced the greenhouse effect as well as achieved the energy mix target in some countries. My research relate to the supply chain system, empowering people's economy and local policy, because Indonesia is unique and having relatively complete strategic policy, yet its operational implementation requires support of various parties for the realization.

Characteristic of developing countries is very strong community participation and fragmented bureaucracy. Through this research, it is expected that the gap between strategic policy and operational policy can be harmonious 
and mutually supportive. My research contribution to science is : giving incentive in form of ease of licensing, feed in tariffs, energy mix mandates (as shown in the previous studies in various countries), will not give a huge boost to renewable energy use advancement in Indonesia, if it is not supported by the appropriate model supply chain to utilize Forest Plantation.

\section{Research and methods}

The study was conducted with the soft system methodology (SSM) through seven stages, namely : (i) identification of problems facing the situation (ii) express the problem statements in form of rich picture (iii) develop root definition in accordance with purposeful activity system (iv) designing the conceptual model based on the root system definition (v) comparing conceptual model of the problem situation (vi) Discussion of desired changes and (vii) remedial action as a solution [2]. This approach is attempted to understand the problems that are complex and dynamic. Stages of the research conducted are literature review, expert surveys and focus group discussions (FGD). Focus group discussions carried out to bring the strategic assumptions with Strategic methods Assumption Surfacing and Testing (SAST) and expert surveys by method of Interpretive Structural Modeling (ISM) [3]. The ISM method is to determine key elements, hierarchical structure and identify the characteristics of the subelement based on the level of dependency and power driver. Related systems approach to problem solving is done through the system analysis and engineering policy. The method, analyzing the system done by six stages such as (i) analysis (ii) problem formulation (iii) identification system (iv) alternative solutions establishment (v) determination of the realization, and (vi ) validation.

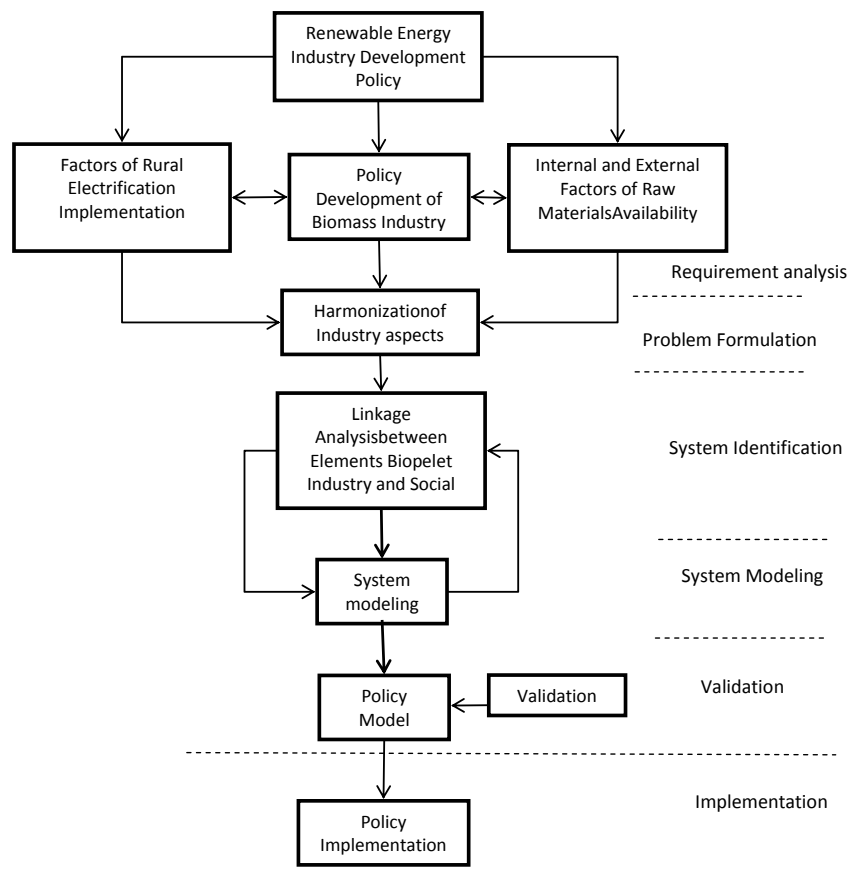

Figure 2. Research frame work. 


\section{Results and discussion}

Renewable energy policy for the industrial private forest-based biomass has an input controlled or not controlled . Uncontrolled inputs include land use, land use rights, the exchange rate, the price of the product and the market demand. Controlled inputs include appropriate technology, human resources quality, supporting infrastructure, access to finance, supply chain systems and socialization. Input controlled and uncontrolled inputs along with the input environment (legislation, government regulation, public culture and agro-climate) produce the desired output in the form of job creation, the utilization of forest products that are environmentally friendly, Green SME growth, availability of renewable energy, and empowerment people and viable biomass energy rates. In addition to produce the desired output, the output is also obtained in the form of unwanted output: service ability degradation, deforestation, high production costs and low public participation. This undesirable outputs into a feedback to management control and then the controlled input and renewable energy policy for the social forestry-based biomass industry will produce output that controllable. Figure input output system is shown in Figure 3.

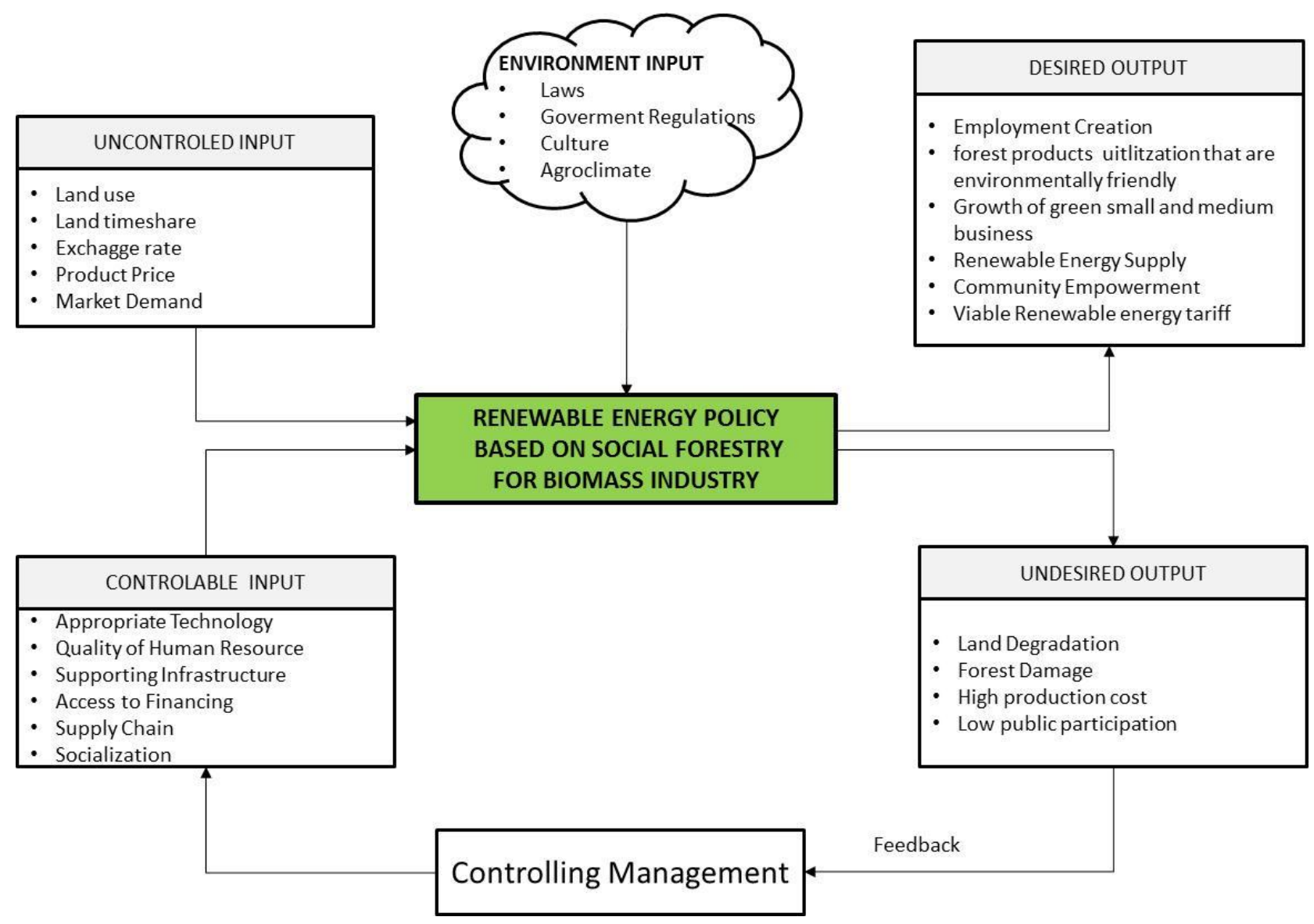

Figure 3. Input output system.

The identification of development of renewable energy problems is described in rich picture diagram (Figure 4), which are three main issues : (i) land status, (ii) environmental degradation and feed in tariff. These three main issues became the basis of goal-oriented activity, resulting root definition: " designing policy of supply chain system 
of biomass industrial as a source of renewable energy based on bio-pellets through the development of bio-pellets which viable economical, insightful environment, involving the business, people and government efforts to achieve sustainability business, community development and rural electrification to support national energy security " .

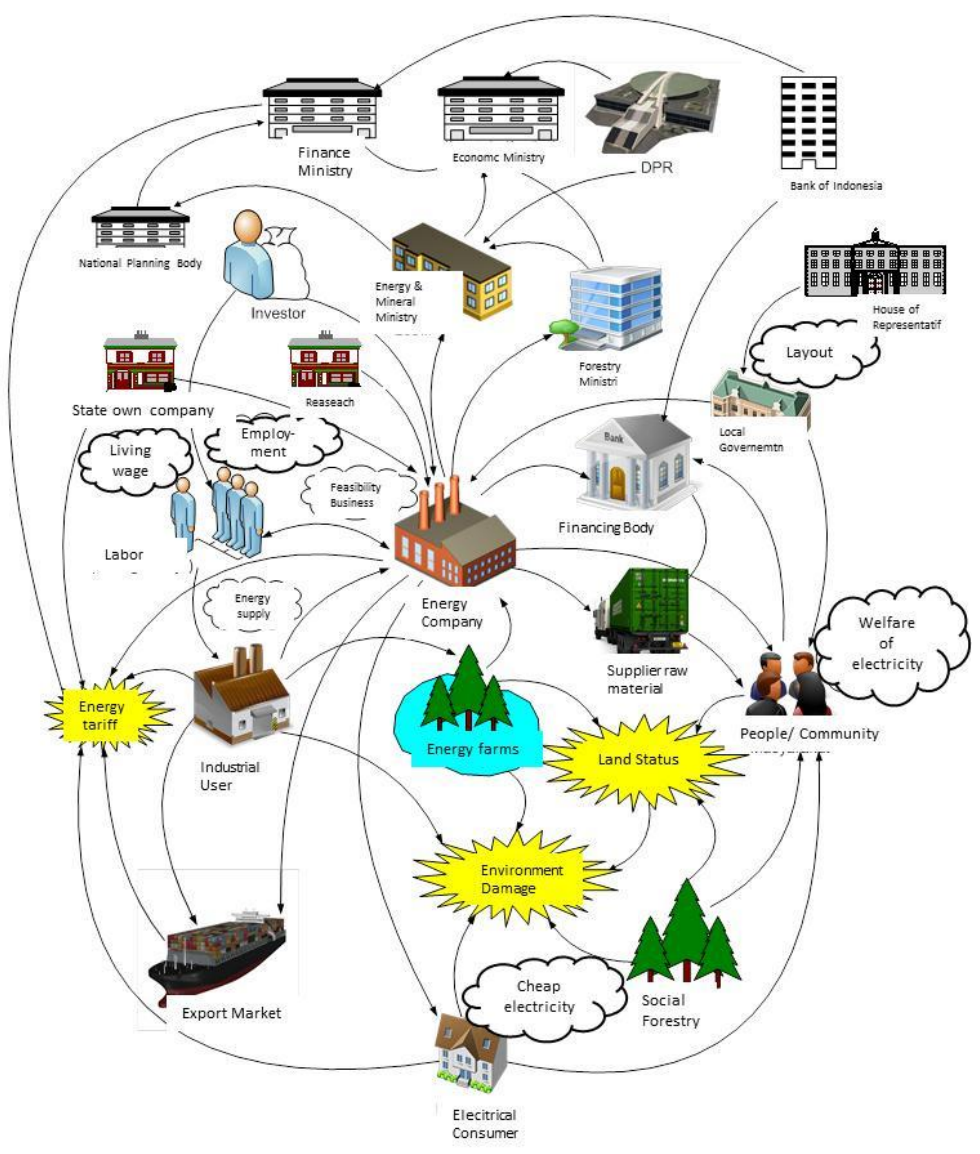

4.1. Structure model development

Figure 4. Rich picture.

Table 1. Key elements of renewable energy development based on bio-pellet.

\begin{tabular}{llll}
\hline \multicolumn{1}{c}{ Key Elemen } & Sub Key Elemen & Dependency \\
\hline 1. & Program goals & Determination of energy tariffs & Increasing public welfare \\
2. & The needs of the program & Raw materials industry \\
& & $\begin{array}{l}\text { The competency of human resources } \\
\text { Coordination between Local Government Offices- } \\
\\
\end{array}$ & \\
& related & \\
& Community participation \\
& Funds \& investment banking business \\
& Micro finance &
\end{tabular}




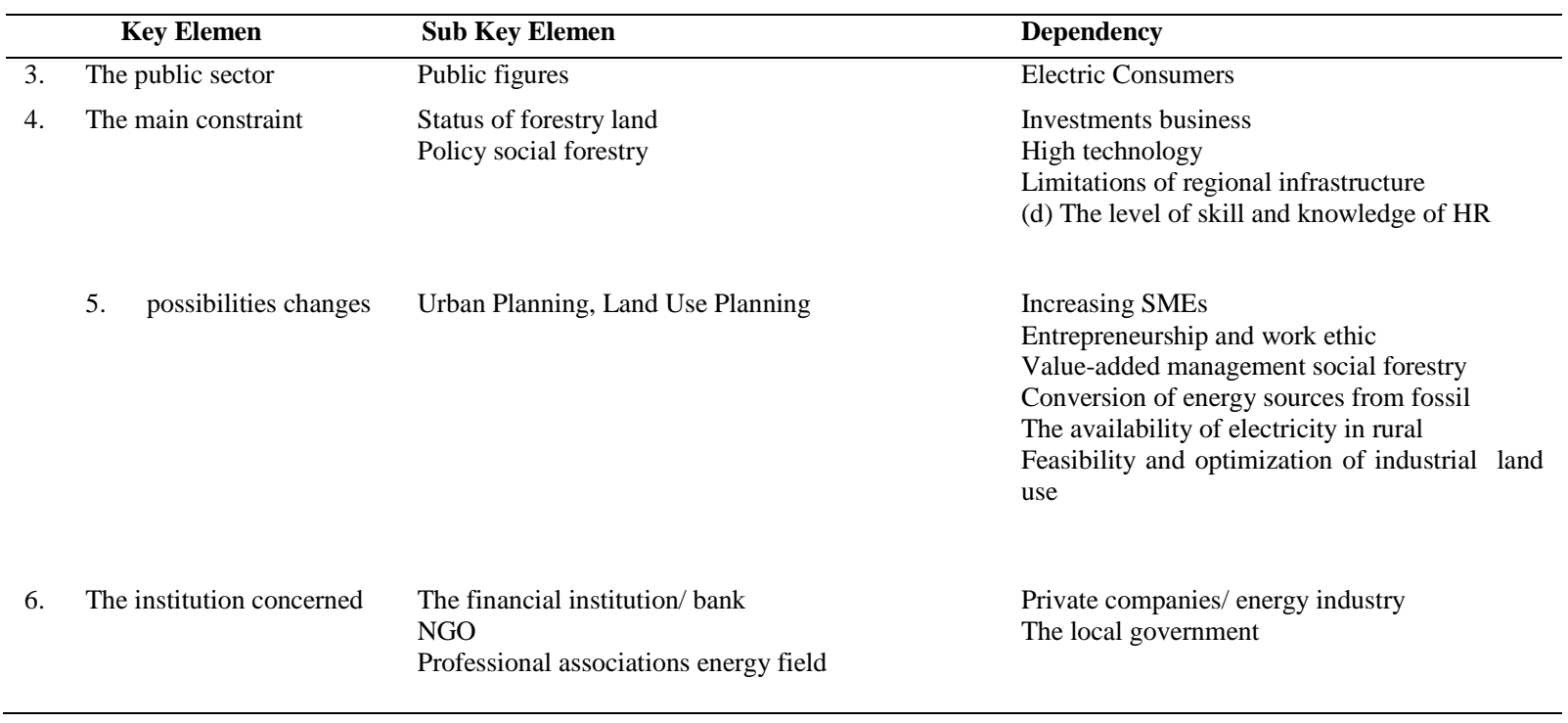

Based on the expert opinion there are six elements of the development program for the renewable energy policy model for biomass industry : (i) program goals (ii) the needs of the program (iii) the public sector (iv) the main constraint (v) possibilities changes and (vi) the institution concerned. By using ISM analysis, obtained driver power-dependence matrix, which shows the key elements of each element as presented in Table 1.

From each element of programs, it was identified sub elements keys, namely the sub element of program goals is the determination of the energy tariff. This shows that the purpose of the energy rate determination is independent variables in the energy policy system and as driving force to the higher level program but small dependency to small program. In the context of bio-pellet industry, the economically viable feed in tariff contributes the achievement of social forestry empowerment and social welfare improvement.

\subsection{Assumptions strategic development model}

The basic assumptions of the renewable energy policy development model for sustainable biomass industry were obtained from Focus Group Discussion (FGD). The results of these discussions led to 27 assumptions which grouped in three aspects: environmental, social, and economic. The assessment from expert based on level of importance and level of certainty identification drives to strategic assumption as shown on Figure 5. Strategic assumptions are in quadrant II, which has a level of importance and high certainty. The assumptions of the environmental aspects: sufficient supply of raw materials, availability of potential alternative industrial biomass raw materials in local, decreasing environmental damage, land and forest inventory, as well as agro-climatic suitability.

Strategic assumptions for social aspects are: support from community leaders, people involved and supporting the program implementation, support regulatory (licensing) and local governments, as well as well-distributed information and dissemination of biomass. The strategic assumptions for economic aspect are : can be used as a new energy source for local, Investors seriousness and commitment, support investment regulation, increased income, the existence of a clear trade system, and there is market potential for both local and export (underwriting market). 


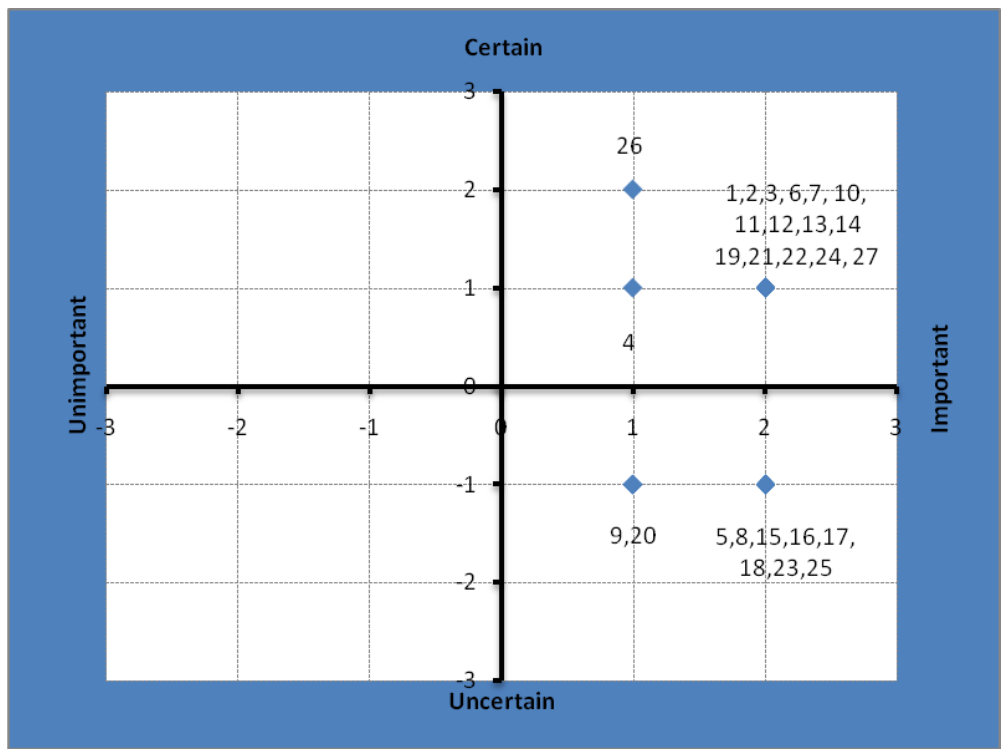

Figure 5. SAST quadran assumption.

\subsection{Intermediate objective map}

Key elements of the program and the resulting strategic assumption surfacing testing used as intermediate objectives map as a connection the ultimate goal of the policy model. Map objectives are expressed as claims i.e. claims of : (i) Forest resources preservation (ii) Energy forests development (iii) Bio-pellet industry as green business (iv) Viable Bio-pellet industry, and (v) Bio-pellet industry provider for rural electrification. Renewable energy policy for rural electrification is strongly associated with the industrial feasibility of energy generation feedstock providers. This is based on the existence of appropriate economical energy prices, fiscal incentives system and government policy for mandatory, this claim as shown on Figure 6.

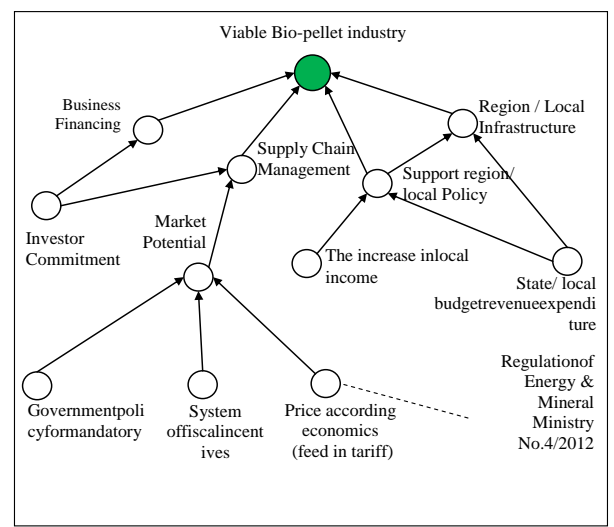

Figure 6. IOM Viable Bio-pellet Industry. 


\section{Conceptual models and implication}

\subsection{Conceptual models}

Based on this approach, two models were developed model of Bio-pellet industry investments for electrification (Figure 7) and the model of supply chain as well as the empowerment of social forestry (Figure 8).

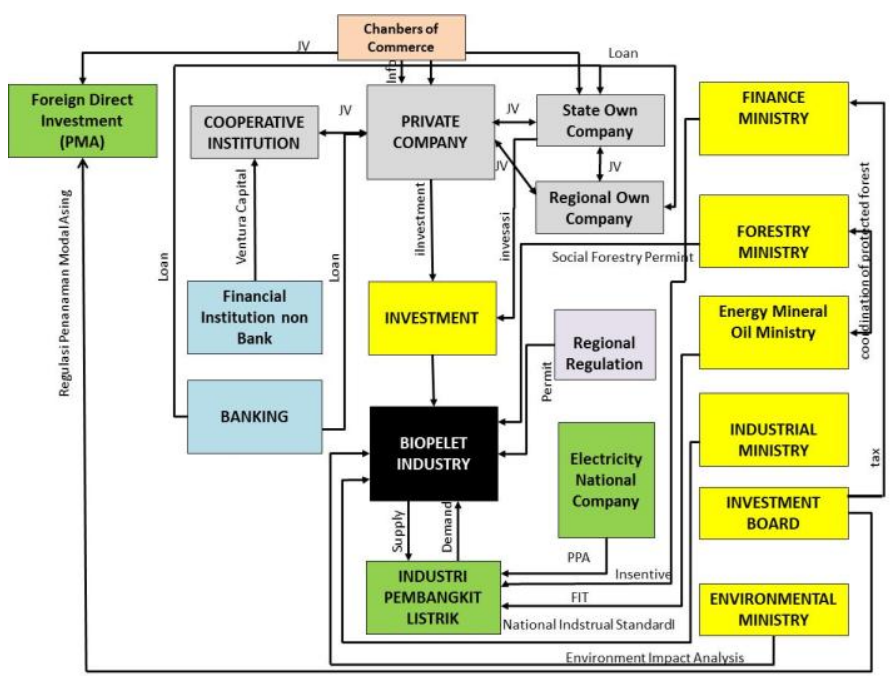

Figure 7. Model of Bio-pellet industry investment.

\subsection{Implications}

The policy implication is a logical consequence of the policy establishment. The research which formulated a renewable energy model policy, based on the community plantation forests for a sustainable biomass industry, entails the consequences of something that should be done so the model can work effectively. The policy implication of this research can be divided into three sections, namely (i) supply chain biopelet, (ii) feed in tariff determination and (iii) the empowerment of smallholder plantations. Explanation for each of the policy implications are described as follows :

\subsubsection{Supply-chain bio-pellet}

Implementation of supply chain bio-pellet model can run more effectively if supported by an integrated policy between energy policy, forestry as energy garden and bio-pellet use mandatory as steam power plants mixer, in this case derived from coal. China made a "supply-chain model" from the landing area to biorefinery, including biomass harvesting, transportation, \& storage. Supply chain model is evaluated using some criteria such as raw material expenses, energy consumption and green house gas (GHG) [4]. China's policy framework on renewable energy regulation has mature and evolved since 2005. This regulation were had updated in 2009. China renewable energy targets in 2020 are similar to Europe. Yet, China continues to face many challenges in technology development, integration network, and policy framework. This challenges include training, research and development, operational experience of wind turbines and its performance, transmission constraints, interconnection network time in the remote area, resource assessment, integration of electricity network on large scale, and further policy development and its adjustment [5]. Substitution process of energy use has to be accompanied with innovative equipment and industrial machines that can support the use of alternative energy and can minimize negative effects of alternative energy use[6]. Bio-pellet industry is quite profitable with 3.6 years BEP at investment of Euro 193600 for a 7.5 ton per hour plant capacity [7]. 


\subsubsection{Feed in tariff determination}

In Ireland, Feed In Tariff determination applied by comparing the tariff structure / FIT design sensitivity to market prices specification errors [8]. Similar as in Japan, there has to be indepth analysis about the renewable energy technology so Feed in Tariff price can actually be accounted for and have the reliability of the technology [9]. In the UK, the way of promote biomass production industry is by forcing power industry through Renewable Energy Obligation. Incentives also given to small-scale power industry through the Feed-in Tariff Scheme, which is purchase electricity to the grid at a certain price guarantee in long term to encourage investments so renewable energy target fulfillment can be quickly achieved. Indonesia has set long-term goals, but more importantly is targeting between what to be achieved at this time, because long-term goals will not be achieved if short term target simply not fulfilled. As any renewable projects in the UAE, government directly pays most of the tariff as feed in tariff substitute or equivalent incentives [10].

In order to achieve targets, Government needs to give the regularly evaluated Feed-in Tariff to encourage private sector in developing biomass-based renewable energy. i.e. bio-pellet. Co-firing coal with biomass is $5 \%$ to $10 \%$ [11]. The Feed-in Tariff will cover production, transportation, generator and the raw materials costs. There is a need to have fixed price per kWh for renewable energy power plants developed by Small and Medium Enterprises [12]. In order to stimulate further participation of private sector in developing alternative energy from upstream to downstream, the government needs to provide convenience, flexibility, and incentives for companies interested in developing alternative energy. Meanwhile, to encourage people using alternative energy, it needs disseminated to the public intensively [6]. ICCC consider the five basic requisite policies to attract more renewable energy investment, especially in the electricity of biomass sector: (i) The availability of biomass raw material (ii) Eliminate investment barrier (iii) Providing investment incentives (iv) Conviction of cancellation and (v) Presenting investment opportunities with sufficient information [13]. Based on iteration made of sensitivity analysis on Feed-in Tariff and US dollar (USD) exchange rate against Indonesian Rupiah (IDR), the results as in the following table:

Table 1. Feed in tariff sensitivity.

\begin{tabular}{cccc}
\hline FIT (US\$c) & USD RATE (IDR) & IRR & BEP \\
\hline 11 & 11,643 & $13.67 \%$ & $7.5 \mathrm{yrs}$ \\
\hline 12 & 11,643 & $15.32 \%$ & $7 \mathrm{yrs}$ \\
\hline 14 & 11,643 & $18.45 \%$ & $6 \mathrm{yrs}$ \\
\hline 11 & 10,000 & $12.76 \%$ & $8 \mathrm{yrs}$ \\
\hline 12 & 10,000 & $14.46 \%$ & $7 \mathrm{yrs}$ \\
\hline 14 & 10,000 & $17.66 \%$ & $6 \mathrm{yrs}$ \\
\hline
\end{tabular}

Minimum Feed-in Tariff of 12 cents USD to get an IRR of at least $14 \%$ required by PLN to obtain a Power Purchase Agreement. This condition assumes USD interest rate of at least IDR 10 000/ USD. These conditions need government regulation that specifically regulates Feed-in Tariff for private bio-pellet. Private sector would be interested to invest as independent power producers to scale up to $10 \mathrm{MWatt}$, so auction process (tender) is not necessary. Minister Regulation equipped with the bio-pelet Feed-in Tariff, will complement ESDM Minister Regulation No. 4 year 2012 and No. 19 year 2013 regarding biomass Feed-in Tariff. 


\subsubsection{Social forestry empowerment}

Empowerment of Social Forestry Model can run more effectively if supported by Social Forestry policy that encourages energy garden. Energy garden is expected to support Energy Security so Indonesia has energy sovereign in the future. The energy security is so important that in LEMHANAS (National Resilience Agency), this security formulated and analyzed along with energy experts. Social Forest Policy had already existed in Indonesia through Government Regulation No. 6 year 2007. It is stated that Social Forest (HTR) is the plantation forest in production forest which built by community groups to improve the potency and quality of production forest by applying civilcultural in order to ensure the forest resources sustainability. Social Forest as a sustainable energy garden policy is needed, because Social Forest in the community more widely used wood as building materials and household equipment, not as energy source. The paradigm in public has not yet toward energy garden, so it needs to be introduced that Forest Plantation is an ideal alternative for eco-friendly energy garden because it is sustainable and can fulfill local energy needs.

Energy estate on private forest lands policy should be regulated by joint decree of the Minister of Forestry and the Minister of Energy and Mineral Resources so people can utilize sustainable social forests as much as possible, and keep maintaining the environment. In India, sustainable forestry scenario aimed to meet biomass demand, stopped deforestation and regeneration of degraded forests are developed and analyzed for mitigation and cost effectiveness for the country. The implementation of appropriate policies and financial incentives on all wood industry, sawn timber and firewood fulfilled through commercial forests, so government funds can be dedicated to preserving the state-owned forests and met the needs for biomass [14]. India and China were already doing serious activity for energy crop cultivation. They are faced with conflict of interest problem between food and energy needs. Marginal land utilization alone will not suffice their needs. India has nine Biomass Research Center at different agro-climatic zones that examines grow rapidly energy crops with high yields and short rotation, while for China with rapidly growing economy, raw materials shortage fulfilled by importing raw material. Indonesia, which has great potency in bio-pellet, should utilize the domestic and international momentum developing bio-pellet, supported with balanced policy so Indonesia would not become another country's energy garden target. The society need to be educated to plant energy gardens with Sengon (Albizia chinensis) trees and this implementation is profitable enough of 5 years BEP, $32 \%$ IRR and cost of Rp34 million per Hectare [15].

\section{Conclusion and recommendation}

\subsection{Conclusion}

- Based on ISM from six analyzed elements, there are influenced factors of social forest biomass based renewable energy policy i.e. the determination of the energy tariff, competent human resources, coordination between related local government offices, incentives system, community participation, banking and investment business fund, microfinance and the need of local governments to design spatial and territories area. These factors should involving Financial Institutions, NGOs and Professional Associations.

- Bio-pellet industry supply chain model with sustainable community forest empowerment need to be supported by the Central Government, including the Ministry of Forestry , Ministry of Environment, Ministry of Industry , Ministry of Energy and Mineral Resources and Ministry of Commerce, Local Government, Financial Institutions, Research Institutions and Private Companies. This system should be supported by The Central Government through various policies to maintain bio-pellet social forest based industry sustainability.

- Biomass based industry renewable energy policy model for rural electrification involving Small and Medium Enterprises. The model is very dependent on non-banking agency fund to make feasibility study as a condition of State Power Company (PLN) power purchase agreement. This funding access becomes important for achieving the next step of rural electrification. 
- According to developed structural model, Independent power producer (IPP) driving the growth of green business growth model for unused land utilization throughout Indonesia and ex-mined land. According to SAST and ISM on developed model, then IPP just can occurred when the private sector get full support from community leaders and civil society to ensure the sustainable energy garden implementation.

- IRR Sensitivity for Biomass Power Plant is minimum FIT of USD 12 cent with IDR / USD exchange rate at least 10 000/ USD to obtain PLN required minimum IRR of $14 \%$.

\subsection{Recommendations}

- This study can be continued for any type of renewable energy technology, based on the scale of power, the power plant site, and the technology used. Rent seeking and coordination bureaucracy are the issues for further policy research topic of renewable energy in Indonesia.

- Feed in tariff should be increased at least US\$12 cent per $\mathrm{KwH}$, and government should facilitate the access to financial institutions for Independent Power Producers of renewable energy and local government should declare the regional planning for energy estate.

\section{Acknowledgements}

Thank you for The Chairman of Local Government Planning - West Sumbawa Region for supporting this research.

\section{References}

[1] Shen L, Liu L, Yao Z, Liu G, Lucas M. 2010. Development Potentials and Policy Options of Biomass in China. Journal of Environment Management. 4(2) : 230 - 245.

[2] Checkland P Scholes J. 1990. Soft System Methodologies in Action. New York (US): John Wiley \& Sons.

[3] Saxena JP, Sushil, Vrat P. 1992. Hierarchy and classification of program plan elements using interpretative structural modelling. System Practice 5(6): 651-670.

[4] Zhang F, Johnson DM, Johnson MA, Sutherland JW. 2011. Development of a Biomass Supply Chain for Biofuel Production. Journal of Applied Sciences. 3(2): 350.

[5] Martinot E. 2010. Renewable power for China: Past, present, and future. New York (US): Energy and Power Pr.

[6] Huang BN. 2008. Causal Relationship Between Energy Consumption and GDP Growth Revisited: A Dynamic Panel Data Approach. Boston (US): Ecological Economics Pr.

[7] Smart. 2009. Bioenergy Commercial Agricultural Pellet Proposal (BECAP) Phase 1 Feasibility Study. Manchaster (GB) : Manchaster University.

[8] Niall F, Mel TD, William TL, James PG, Sean L. 2013. Specifying An Efficient Renewable Energy Feed-in Tariff. Limerick (IF) : University of Limerick Pr.

[9] Ikeda J. 2013. Renewable energy: Taking advantage of the feed-in tariff regime. Tokyo (JP): Financial Law Pr.

[10] Varriale G.2013. The keys to renewable energy success in the Middle East. International Financial Law Journal. 4(2) : 455-470.

[11] Craig F.2009. Renewable energy in Australia: 20 per cent by 2020: Can this be achieved? Quensland (AU): Univesity of Quensland. Australia.

[12] Lustig. M. 2013. Approves 14 Small Renewable Projects in Feed-in Tariff Program. New York (US): SNL Energi Renewable Energi Pr.

[13] Panjaitan A. 2013. Menarik Investasi Energi Terbarukan Melalui Tanaman. Jakarta (ID) : Indonesia Climate Change Center (ICCC) Pr.

[14] Ravindranath. 2001. Forestry for sustainable biomass production and carbon sequesteration in India. Mitigation and Adaptation Strategies for Global Change. Journal of Forestry 4(5) : $200-214$.

[15] Indira, 2009, Cost \& Benefit Analysis: Kayu Sengon pada PTPN XII (Persero). Surakarta (ID): Universitas Sebelas Maret Pr. 